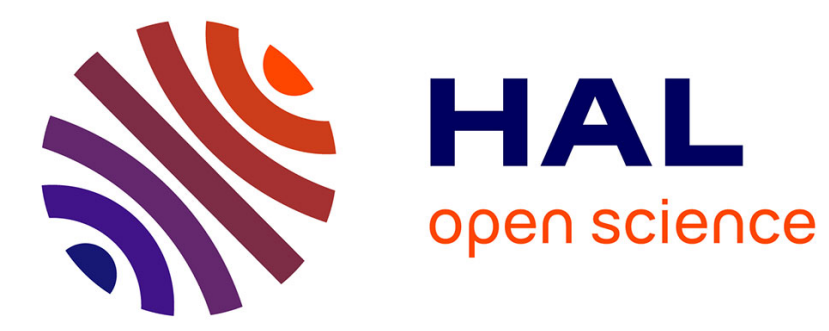

\title{
Nanocellulose Production by Twin-Screw Extrusion: Simulation of the Screw Profile To Increase the Productivity
}

Fleur Rol, Bruno Vergnes, Nadia El Kissi, Julien Bras

\section{To cite this version:}

Fleur Rol, Bruno Vergnes, Nadia El Kissi, Julien Bras. Nanocellulose Production by Twin-Screw Extrusion: Simulation of the Screw Profile To Increase the Productivity. ACS Sustainable Chemistry \& Engineering, 2019, 8 (1), pp.50-59. 10.1021/acssuschemeng.9b01913 . hal-03038346

\section{HAL Id: hal-03038346 https://hal.science/hal-03038346}

Submitted on 4 Dec 2020

HAL is a multi-disciplinary open access archive for the deposit and dissemination of scientific research documents, whether they are published or not. The documents may come from teaching and research institutions in France or abroad, or from public or private research centers.
L'archive ouverte pluridisciplinaire HAL, est destinée au dépôt et à la diffusion de documents scientifiques de niveau recherche, publiés ou non, émanant des établissements d'enseignement et de recherche français ou étrangers, des laboratoires publics ou privés. 


\title{
Nanocellulose production by twin-screw extrusion:
}

\section{simulation of the screw profile to increase the}

\section{productivity}

\author{
Fleur Rol ${ }^{\mp}$, Bruno Vergnes ${ }^{\Psi}$, Nadia El Kissi ${ }^{I}$, Julien Bras $^{*, \mp, 4}$ \\ ${ }^{\mp}$ Univ. Grenoble Alpes, CNRS, Grenoble INP, LGP2, F-38000 Grenoble, France \\ ${ }^{\Psi}$ MINES ParisTech., CEMEF, UMR CNRS 7635, 06904 Sophia Antipolis Cedex, France \\ ${ }^{\text {I}}$ Laboratoire Rhéologie et Procédés, Grenoble INP-CNRS-UJF, UMR 5520, Grenoble, France \\ ${ }^{\Lambda}$ Institut Universitaire de France (IUF), F-75000 Paris, France
}

*Corresponding author

Email: julien.bras@grenoble-inp.fr

LGP2

461 rue de la papeterie

38402 Saint Martin d'Hères

France

Laboratoire Rhéologie Procédés

363 rue de la chimie

38402 Saint Martin d'Hères

France

Cemef

1 rue Claude Daunesse

06904 Sophia Antipolis

France 
KEYWORDS. Cellulose nanofibrils, energy efficient, quality index, Ludovic ${ }^{\circledR}$ software, productivity

ABSTRACT. Cellulose nanofibrils (CNF) have gained increased attention since the last fifteen years and can now be produced at high solid content in an energetically efficient way using twin-screw extrusion (TSE). In this study, screw profile was optimized using a simulation software in order to produce high quality CNF in one pass through the TSE, instead of several passes in other studies, decreasing the energy consumption, improving the productivity and hence making the industrialization of such process more probable. An optimized profile was designed using the software according to previous studies and enzymatic cellulose pulp was experimentally nanofibrillated. Produced CNF were characterized using several techniques such as optical microscopy, mechanical properties, turbidity, nanosized fraction or quality index. The optimized screw profile contains six blocks of kneading disks with left-handed staggering and imparts high levels of shear, strain and energy in the first pass. CNF were successfully produced in a single pass with equivalent quality than CNF produced in at least 4 passes using a classic profile, without changing the energy consumption. Produced CNF present high transparency and a Young's modulus around $13 \mathrm{GPa}$.

\section{INTRODUCTION}

Cellulose nanofibrils (CNF) discovered in $1980^{1}$ can be extracted from cellulose fibers and present indisputable properties such as transparency or barrier properties. CNF can be used in a wide range of applications such as packaging ${ }^{2}$, paper $^{3}$ or medical applications. ${ }^{4,5}$

CNF are produced by a succession of chemical/enzymatical and mechanical processes. Chemical modifications and enzymes are used to weaken cellulose fibers structure and facilitate their nanofibrillation. Chemical modifications such as TEMPO oxidation $^{6}$, carboxymethylation $^{7,8}$ or phosphorylation ${ }^{9-11}$ create charges on cellulose fibers increasing the repulsion and decreasing the $\mathrm{H}$-bonds. Those pretreatments favor the nanofibrillation and decrease the energy consumption of mechanical processes. Moreover, high quality 
functionalized CNF are hence obtained. Chemical pretreatments were recently reviewed by Rol et al. ${ }^{12}$. Various mechanical processes can be used to produce CNF but ultra-fine grinder $^{13,14}$ and homogenizer ${ }^{10,15}$ are the most used. Researches are now turning to energy efficient processes able to produce high solid content and high quality CNF suspensions. Indeed, CNF are traditionally produced at 2-5 wt $\%$ which increases the transport cost and hence the CNF price. Moreover it can cause problems of storage or use in formulations or in some applications where water should be avoided.

Recently, Ho et al. ${ }^{16}$ have shown that twin-screw extrusion (TSE) can be used to produce good quality $\mathrm{CNF}$ at a solid content between 33 and $45 \mathrm{wt} \%$. Non-pretreated cellulose pulp was nanofibrillated in a TSE and CNF with a high transparency (up to $90 \%$ ) and Young's modulus around $6 \mathrm{GPa}$ were obtained after 10 passes. Baati et al. ${ }^{17}$ reported the use of conical mini-compounder to produce TEMPO CNF. CNF with a lateral size between 3 and $7 \mathrm{~nm}$ and high transparency (up to $75 \%$ ) were produced without damaging the crystallinity index of the cellulose. An energy consumption of $4,100 \mathrm{kWh} / \mathrm{t}$ was reported which is lower than the one consumed by the ultra-fine grinder or homogenizer. ${ }^{13,15}$ Other studies also reported the production of CNF by twin-screw extrusion during the compounding with matrices. ${ }^{18-20}$ The production of pure CNF by TSE was also patented. ${ }^{21}$ Finally, Rol et al. ${ }^{22}$ produced CNF using a twin-screw extruder after enzymatic hydrolysis or TEMPO oxidation of cellulose fibers. CNF with the same quality than the one produced by ultra-fine grinder were obtained decreasing the energy consumption of $63 \%$. Moreover, a screw profile was reported for the first time. However, in all studies, several passes through the TSE are required to obtain high quality CNF, which increases the energy consumption and makes the industrialization of such process more complicated.

The main objective of this study is to find a screw profile, and corresponding extrusion conditions, able to produce CNF of high quality in only one pass through the TSE, improving 
considerably the productivity and decreasing the energy consumption. A simulation software called Ludovic ${ }^{\circledR 23}$ was used to determine a proper screw profile. This software has already been used with success since 20 years to understand and simulate twin-screw extrusion in several applications like polymer/composites processing ${ }^{24,25}$ or food processing. ${ }^{26}$

First, CNF were produced by TSE using different screw profiles and characterized. Data were collected and used to calibrate different parameters required in Ludovic ${ }^{\circledR}$ software. After determining how much energy the fibers need to be nanofibrillated thanks to the first experiments, a new screw profile and new extrusion conditions able to provide this energy in one pass were designed playing with the software. It is the optimized screw profile using our extruder and our pulp. Of course, further small optimization can be imagined evaluating the impact of each screw of the screw profile. For now, no conclusion from literature can be drawn on which parameters govern the nanofibrillation of cellulose fibers. That is why the most representative parameters of the TSE are followed along the manuscript. A new profile was designed in order to produce high quality CNF in only one pass and hence favor the production at industrial scale. This study reports the process used to calibrate the software, the determination of the new screw profile using Ludovic ${ }^{\circledR}$ and the comparison of the CNF produced using the proposed new profile or to the previous one.

\section{MATERIALS \& METHODS}

\section{Materials}

The cellulose used throughout this work is eucalyptus bleached kraft pulp from Fibria (Brazil). All the chemicals used for the enzymatic hydrolysis were used as received: enzyme solution, (cellulase, FiberCare ${ }^{\circledR}$ from Novozymes, 4,500 ECU/g), acetic acid (Roth, 99\%) and sodium acetate trihydrate (Sigma Aldrich, 99\%). Distilled water was used in all suspensions. 


\section{Methods}

Ludovic $^{\circledR}$ software. A flow simulation software dedicated to TSE, called Ludovic ${ }^{\circledR}$, was used to optimize the profile and also to estimate the parameters that cannot be measured experimentally such as local shear rates or the cumulated strain. This software is commercialized by Sciences Computers Consultants company (Saint-Etienne, France). Ludovic ${ }^{\circledR}$ calculates the main flow thermomechanical parameters such as temperature, shear rate, residence time and pressure along the screws. The flow is simplified and modeled using a local 1D approach. ${ }^{27,28}$ The software considers non-isothermal flow conditions to determine the temperature evolution. ${ }^{29}$ Different models are used depending on the geometry (screw conveying elements or blocks of kneading disks). A global description of the flow in the TSE is obtained by linking all the models corresponding to the considered screw profile. ${ }^{30}$ First the software was calibrated and the different required parameters were defined using preliminary tests. Then different profiles were designed by the user on the software and the extrusion answers (shear rate, cumulative strain and specific mechanical energy) were simulated until obtaining the screw profile able to provide enough energy in one pass to nanofibrillate the cellulosic pulp.

Cellulose refining. Cellulose fibers were redispersed at $2 \mathrm{wt} \%$ in water and refined using a pilot disk refiner (Matech Paper) equipped with 12" disks until a Schopper Riegler index $\left({ }^{\circ} \mathrm{SR}\right)$ of $90 .{ }^{\circ} \mathrm{SR}$ was measured at least three times according to ISO 5267 standards. The refining step weakens the cellulose fibers and makes the nanofibrillation easier.

Enzymatic pretreatment of cellulose fibers. Refined cellulose fibers at $2 \mathrm{wt} \%$ were then enzymatically treated using cellulase enzymes in order to make the nanofibrillation easier. First the $\mathrm{pH}$ was adjusted at 5 using a buffer of acetic acid and sodium acetate trihydrate and then 300 ECU of enzyme per gram of cellulose were added. The reaction was performed at $50^{\circ} \mathrm{C}$ for $2 \mathrm{~h}$ under stirring. Enzymes were finally killed by increasing the temperature to 80 
${ }^{\circ} \mathrm{C}$ for 15 min. Fibers were washed under filtration with distilled water and finally were pressed until a solid content of $20 \mathrm{wt} \%$. The final $\mathrm{pH}$ of the suspension was 7.

Refining and enzymatic pretreatment are used by CNF producer to make the nanofibrillation easier and thus decrease the energy consumption and improve the CNF quality.

Nanofibrillation by twin-screw extrusion. A twin-screw extruder (ThermoScientific HAAKE Rheomex OS PTW16 + HAAKE PolyLab OS Rheodrive 7) with a diameter $d=16$ $\mathrm{mm}$ and a length $\mathrm{L}=640 \mathrm{~mm}$ was used to nanofibrillate the cellulosic pulp. The TSE was equipped with a volumetric feeder (Thermo-Fisher Scientific, Force feeder, Polylab OS 5674002) to introduce the fibers at $20 \mathrm{wt} \%$ in the TSE at a flow rate of $50 \mathrm{~g} / \mathrm{min}$ (wet). The Do/Di (outer diameter on inner diameter) ratio is equal to 1.77 , the screw center distance is $12.5 \mathrm{~mm}$ and finally the screw channel depth is $3.3 \mathrm{~mm}$. The screw speed was $400 \mathrm{rpm}$ and the barrel temperature maintained at $10{ }^{\circ} \mathrm{C}$ using a cooling system to avoid clogging of the pulp and in accordance with Ho et al. ${ }^{16}$. The screw profiles used are reported in Figure 1. The conveying profile was used as a negative reference. The profiles 1 and 2 contain three shearing zones with equivalent length. The three zones present an increased shearing. The profile 2 presents higher amount of elements at $90^{\circ}$ and will probably have more impact on the fibers. 


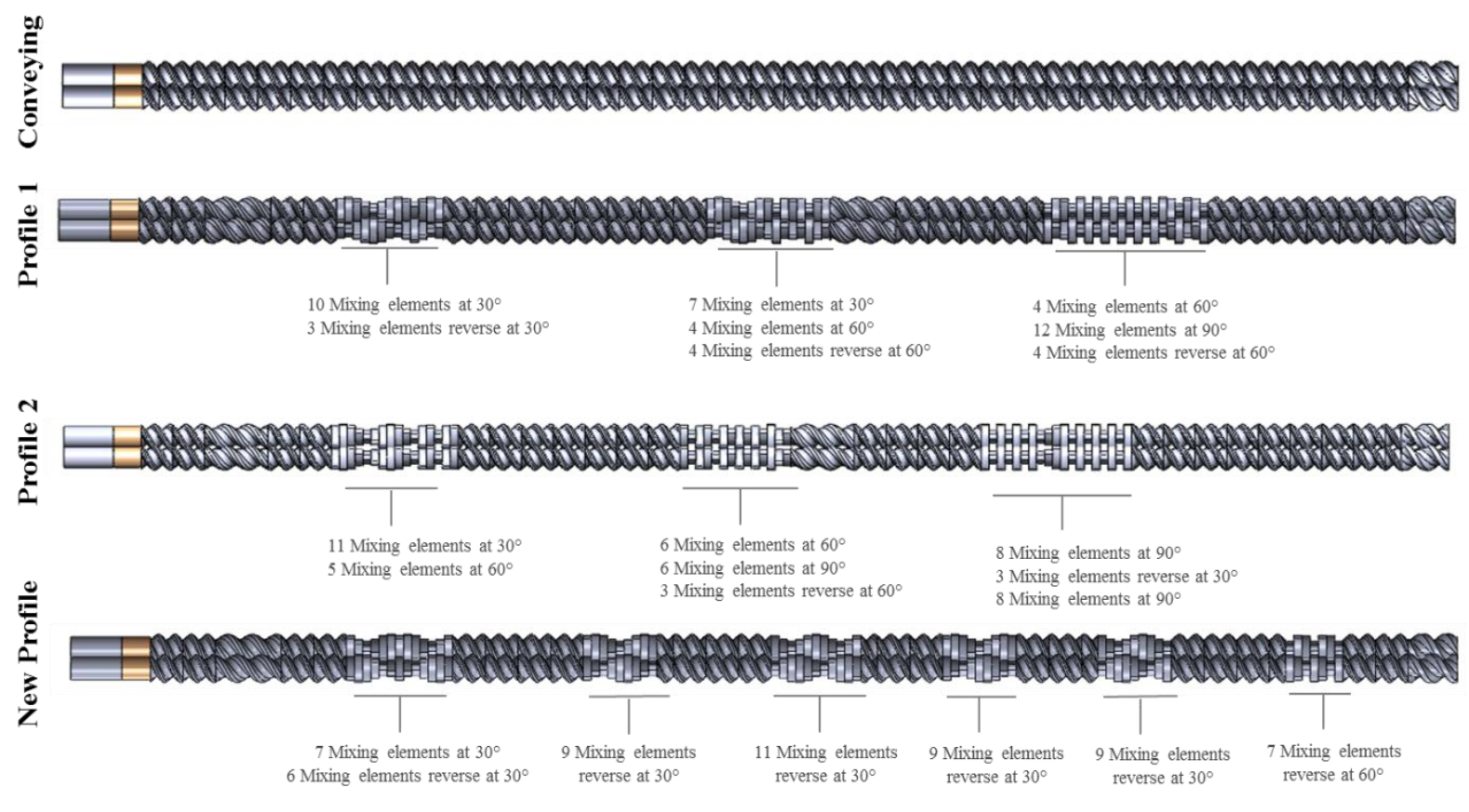

"Figure 1. Screw profiles used for comparison (Profiles 1 and 2) and optimized screw profile (New

$$
\text { profile)." }
$$

Energy consumption used for the nanofibrillation. The energy consumed by the TSE, also called specific mechanical energy (SME), was calculated as follows:

$$
\mathrm{SME}\left[\frac{\mathrm{kWh}}{\mathrm{t}}\right]=\frac{\mathrm{N} * \mathrm{C} * \mathrm{P}_{\max }}{N_{\max } * C_{\max } * Q}
$$

where $\mathrm{N}$ is the screw speed (rpm), $\mathrm{N}_{\max }$ is the maximal speed $(1,100 \mathrm{rpm}), \mathrm{P}_{\max }$ is the motor torque $(7 \mathrm{~kW}), \mathrm{C}(\mathrm{N} . \mathrm{m})$ is the torque, $\mathrm{C}_{\max }$ is the maximal torque $(130 \mathrm{~N} . \mathrm{m})$ and $\mathrm{Q}$ the total flow rate in $\mathrm{t} / \mathrm{h}$. The energies reported here do not take into account the energy consumed by the preliminary refining step, namely $600 \mathrm{kWh} / \mathrm{t}$. When the pulp is passed several times through the TSE, the energies consumed by each pass are added to obtain the total energy consumption.

The characterizations of CNF suspensions is a challenging topic. Several direct or indirect methods can be used characterizing the nanometric part or the micrometric part. That is why different methods should be used to characterize CNF suspension. 
CNF nanopapers \& films preparation. Nanopapers at $60 \mathrm{~g} / \mathrm{m}^{2}$ were produced using a standard paper sheet former (Rapid Köthen, ISO 5269-2) equipped with a nylon sieve with a mesh size of $1 \mu \mathrm{m} .10 \mathrm{~g}$ of $\mathrm{CNF}$ at $20 \mathrm{wt} \%$ were diluted to $1 \mathrm{wt} \%$ and dispersed using an Ultra-Turrax for $1 \mathrm{~min}$ and filtered on the sheet former before drying under vacuum at $90{ }^{\circ} \mathrm{C}$ for $20 \mathrm{~min}$. Casted films at $45 \mathrm{~g} / \mathrm{m}^{2}$ were also produced. $1.5 \mathrm{~g}$ of CNF at $20 \mathrm{wt} \%$ were diluted into $50 \mathrm{~mL}$ of water and dispersed using an Ultra-Turrax for $1 \mathrm{~min}$ before casting in Petri dishes and drying in a conditioned room $\left(25^{\circ} \mathrm{C}, 50 \% \mathrm{RH}\right)$ for 7 days. Samples were stabilized in conditioned room before any analysis.

Rheology measurements. Samples were stored at least one week in the fridge and rheology measurements of this high solid content cellulosic pulp were conducted using a rheometer ARG2 (TA instrument) equipped with a protective hood to prevent the samples from possible drying or moisture absorbing. A ball of $1 \mathrm{~g}$ of refined enzymatic cellulosic pulp, extruded or not, at $20 \mathrm{wt} \%$ was premixed by hands and placed under the parallel plate geometry with a diameter of $25 \mathrm{~mm}$. Geometry was moved down slowly until the required gap and the excess of pulp was removed carefully using a spatula. Measurements in small amplitude oscillatory shear at $15{ }^{\circ} \mathrm{C}$ were carried out. Oscillatory measurements were performed to determine the linear domain. Strain sweep experiments at an angular frequency of $10 \mathrm{rad} / \mathrm{s}$ were performed and the optimal strain was determined at $0.02 \%$. The measurements were then conducted in the range of 0.1 to $100 \mathrm{rad} / \mathrm{s}$ at a fixed strain of $0.02 \%$. Measurements were done at least twice per sample. Determining the rheological behavior of cellulosic pulp at $20 \mathrm{wt} \%$ is challenging.

Optical microscopy. CNF suspensions were diluted to $0.5 \mathrm{wt} \%$ using an Ultra-Turrax for 1 min and were observed using an optical microscope (Carl Zeiss Axio Imager M1) equipped with an AxioCam MRc 5 digital camera and optical images were taken. At least ten images were taken and the most representatives are shown here. Images were then analyzed using Image J software. 
Transmission electron microscopy (TEM). The CNF at $20 \mathrm{wt} \%$ obtained with the TSE equipped with the different profiles was diluted to $10^{-3} \mathrm{wt} \%$. A drop was then casted on a copper grid covered with amorphous carbon. The images were then obtained using a transmission electron microscope (FEI/Philips CM 200) with an accelerating voltage of 200 $\mathrm{kV}$ equipped with a camera (TemCam F216, TVIPS). At least 10 areas of the grid were observed and the most representative are shown here. CNF diameters were measured on TEM images using ImageJ software.

Suspension morphology. CNF suspensions morphologies were analyzed using MorFi LB-01 fiber analyzer (Techpap, France) on precisely $0.3 \mathrm{~g}$ of fibers, namely $1.5 \mathrm{~g}$ at $20 \mathrm{wt} \%$. The MorFi analyses the morphology of cellulose fibers suspensions and is based on optical images analysis. This technique allows to characterize the residual fibers present in heterogeneous CNF suspensions and does not give information on the nanometric part. It is also used to compare different CNF suspension in terms of remaining big fibers. The images are taken by a camera on a suspension of fibers in movement. The data exploited are fiber content in millions per gram of pulp and fine content in $\%$ in area. A minimum of 20,000 fibers were counted before stopping the analysis and the fiber/fine limit was set at $80 \mu \mathrm{m}$.

Degree of polymerization of cellulose (DP). DP was evaluated using the ISO 5351:2010 standard. $500 \mathrm{mg}$ of equivalent dry cellulose nanofibrils suspension, which corresponds to $2.5 \mathrm{~g}$ at $20 \mathrm{wt} \%$, was dissolved in a mix of $25 \mathrm{~mL}$ of copper (II) ethylenediamine and $25 \mathrm{~mL}$ of distillated water for $2 \mathrm{~h}$ under stirring. The intrinsic viscosity was measured at least three times and the DP was determined using the Mark Houwink Sakurada equation.

Nanosized fraction. CNF were diluted to $0.02 \mathrm{wt} \%$. $0.4 \mathrm{~g}$ of CNF at $20 \mathrm{wt} \%$ were weighted and diluted in $400 \mathrm{~mL}$ of water. The obtained suspension at $0.02 \mathrm{wt} \%$ was centrifuged at $1,000 \mathrm{~g}$ for $15 \mathrm{~min}$ using a centrifuge (Sigma 3-18 KS, Germany). Nanosized fraction was calculated according to Naderi et al. ${ }^{15}$ protocol by dividing the exact concentration of the 
suspension after the centrifugation (at the top of the bottle, at around $1 \mathrm{~cm}$ from the top) by the concentration of the suspension before the concentration. The test was done a minimum of three times and the average is presented here.

Turbidity. CNF suspensions were diluted to $0.1 \mathrm{wt} \%(0.5 \mathrm{~g}$ of CNF at $20 \mathrm{wt} \%$ were diluted in $100 \mathrm{~mL}$ ) and turbidity was measured using a portable turbidimeter AL $250 \mathrm{~T}$-IT, AquaLytic with a range between 0.01 and 1,100 NTU. A minimum of 10 measurements were done and the average is presented here.

Transmittance. Transmittances at $550 \mathrm{~nm}$ were measured on casted CNF films using an ultraviolet spectrophotometer (Shimadzu USA MFC Inc., 70158) in order to evaluate the transparency of CNF films. At least ten measurements were done on each film and the average is represented here.

Mechanical properties. Young's moduli of nanopapers were measured using an Instron 5965 machine equipped with a load cell of $5 \mathrm{kN}$ capacity. Specimen of 100 x $15 \mathrm{~mm}$ were prepared and tested at a cross-head speed of $10 \mathrm{~mm} / \mathrm{min}$. At least five tests were done for each sample and the average is presented here.

Macro size. The macro size reports the average size of microparticles and it is measured on optical images using the Image J program. Images were converted to 8-byte type, thresholded and then the average size of the remaining particles was measured using the analyze particles mode of the software. The obtained value is calculated by dividing the average surface area of visible particles by the number of counted particles.

Quality index. CNF quality was evaluated using the simplified quality index QI* developed by Desmaisons et al. $^{31}$. Four simple and easy tests were done and $\mathrm{QI}^{*}$ was calculated as follows: $Q I^{*}=0.3 \mathrm{x}_{1}-0.03 \mathrm{x}_{2}-0.072 \mathrm{x}_{3}^{2}+2.54 \mathrm{x}_{3}-5.34 \ln \left(\mathrm{x}_{4}\right)+58.62$ 
where $\mathrm{x}_{1}=$ nanosized fraction $[\%] ; \mathrm{x}_{2}=$ turbidity $[\mathrm{NTU}] ; \mathrm{x}_{3}=$ Young's modulus $[\mathrm{GPa}] ; \mathrm{x}_{4}=$ macro size $\left[\mu \mathrm{m}^{2}\right]$ measured using Image $\mathbf{J}$ software and optical microscopy images. All of this techniques were explained previously. 


\section{RESULTS \& DISCUSSION}

CNF were produced using different screw profiles (Figure 1) and characterized. ${ }^{31-33}$ The obtained data were used to calibrate the software with this new material and then to design the profile which will allow producing CNF in one pass.

\section{Calibration of the simulation software}

Different data are required for the computation: the screw profile, the operating conditions (feed rate, screw speed and regulation temperature) and the material properties. Material intrinsic properties, such as thermal conductivity, heat capacity and density, were calculated from those of water and cellulose. Indeed, the material extruded is a mix of $80 \%$ of water and $20 \%$ of cellulose and such parameters are not available for this kind of material.

The rheological behavior of the cellulose pulp in the TSE, required by the software, was evaluated using the rheological measurements made on the enzymatic cellulosic pulp after different passes through the TSE (Figure 2 a,b ). The material exhibits a gel-like behaviour and follows a power law. The complex viscosity $\eta^{*}$ can be expressed as follows:

$$
\eta^{*}=K \omega^{m-1}
$$

where $\omega$ is the angular frequency, $\mathrm{K}$ is the consistency and $\mathrm{m}$ is the power law index. 
(a)

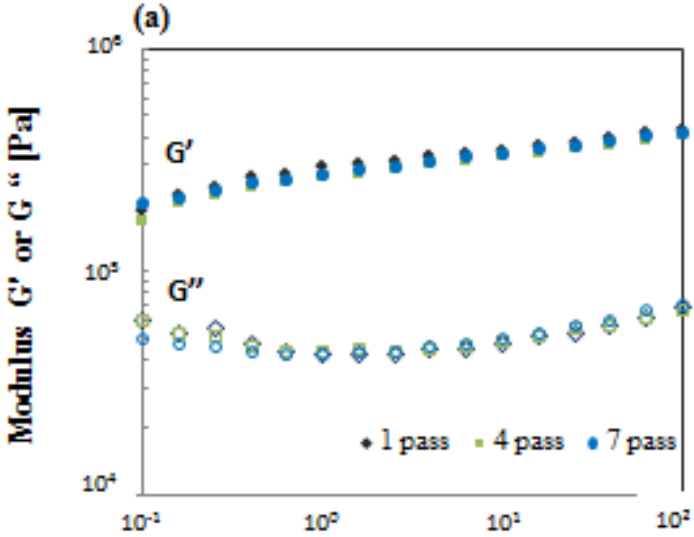

(c)

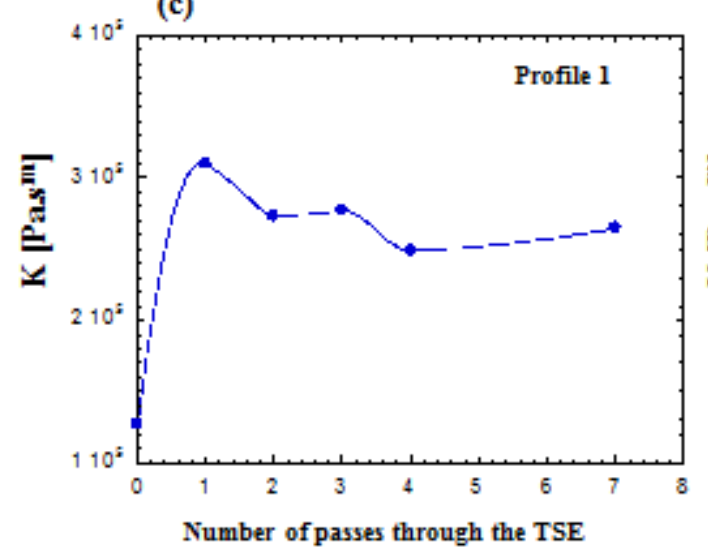

(b)

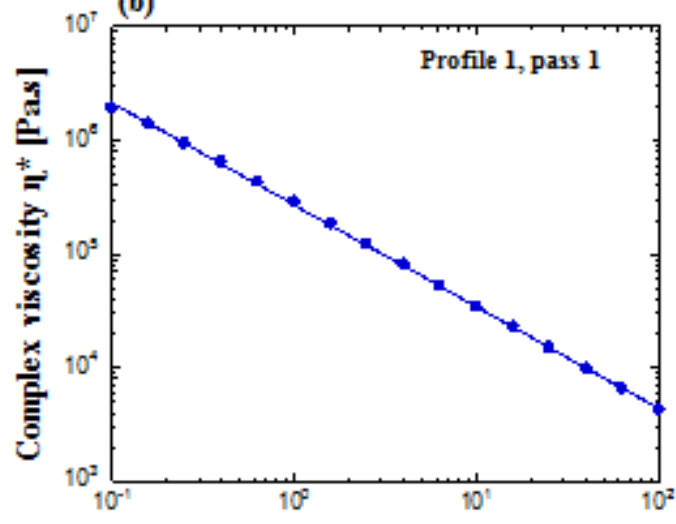

(d)

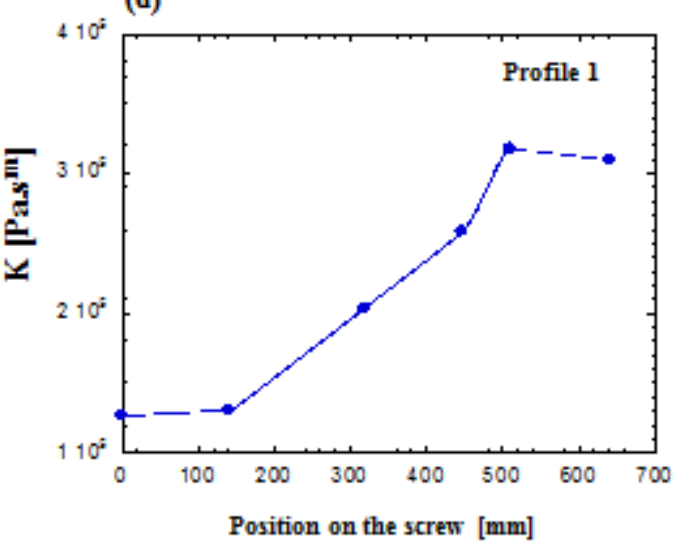

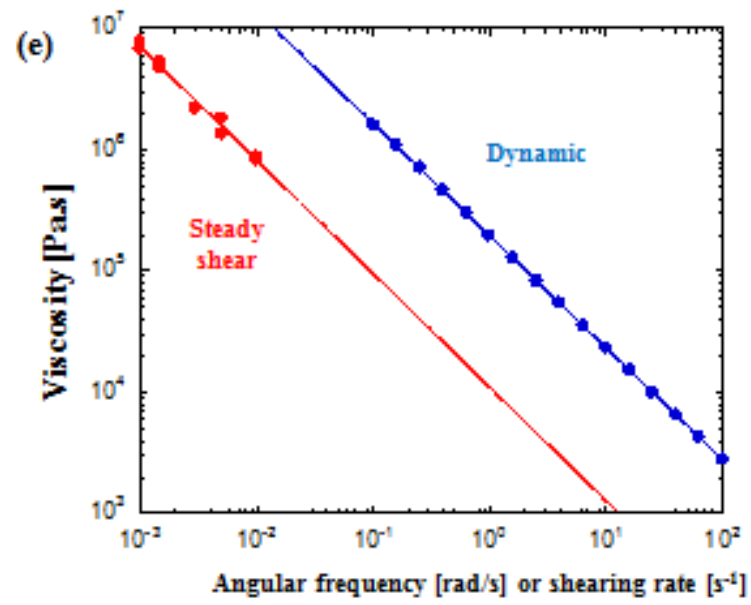

"Figure 2. Rheological behavior of enzymatically treated cellulose pulp passed once or several times through the TSE: Determination of the rheological behavior with (a) evolution of the storage modulus G' (filled dots) and the loss modulus G" (blanck dots) with angular frequency, Determination of the viscosity law with (b) the evolution of the complex viscosity with angular frequency, Evolution of the viscosity law with $(\mathrm{c}, \mathrm{d})$ the change of consistency $\mathrm{K}$ with the number of passes or the position along the screws and (e) comparison of complex and shear viscosity of the CNF suspension." 
Rheological measurements were carried out using a new protocol adapted for CNF at 20 wt\%. G' is much higher than G', which indicates a solid-like behavior already reported by Baati et al. ${ }^{17}$ for a CNF concentration of $10 \mathrm{wt} \%$. CNF have a 3D interconnected structure network and, depending on the quality, the network strength can change. When quality increases, specific surface area increases and higher entanglement occurs leading to a stronger network. ${ }^{34,35}$ Data of G' and G'" reported here are really high compared to the literature but are very dependent on the protocol used and on the solid content. Viscosity is much higher than for an ultra-fine grinder ${ }^{36}$ at $1.8 \mathrm{wt} \%$ but it is well-known that viscosity strongly increases with the CNF suspension solid content. ${ }^{37-40}$ Rheological behaviors of the pulp during the first pass and with the evolution of the number of passes in the TSE were measured in order to determine the factors $\mathrm{K}$ and $\mathrm{m}$ of the viscosity law, as exposed in Equation (3), required by the software (Figure $2 \mathrm{c}$, d). If $\mathrm{K}$ increases with the position along the screws and number of passes, $\mathrm{m}$ remains almost constant, around 0.1 , which indicates a shear-thinning behavior. $^{36,41}$

The cellulosic pulp was also characterized in large deformation (continuous shear) to check if the Cox-Merz ${ }^{42}$ rule was valid or not. For many molten polymers, the dynamic viscosity in function of the frequency $(\omega)$ is equivalent to the shear viscosity in function of the shear rate $(\dot{\gamma})$ when $\omega=\dot{\gamma}$. As expected and shown in Figure 2,e, the Cox-Merz rule cannot be applied to $\mathrm{CNF}$ suspensions and the viscosity in large deformation is 10 to 20 times lower than the complex viscosity. The flow in the TSE breaks the pulp structure, which thus becomes more fluid: the consistency $\mathrm{K}$ passes from 310,000 Pa.s ${ }^{\mathrm{m}}$ in oscillatory shear to 11,000 Pa.s ${ }^{\mathrm{m}}$ in continuous shear. Obviously, this influences strongly the results of the simulation. Therefore, in the following, the complex viscosity data were always divided by 10 for the simulation. It is enough to obtain correct orders of magnitude for the purpose of the optimization. 


\section{Comparison of the previous screw profiles used to produce CNF}

Different screw profiles have been tested, passing the enzymatic cellulosic pulp several times through the TSE and CNF obtained were characterized. The results were used for the calibration and to check the efficiency of the simulation using the software. For each profile, the quality is usually stabilized above $600-700 \mathrm{kWh} / \mathrm{t}$ humid (or 3,000 - 3,500 $\mathrm{kWh} / \mathrm{t}$ dry), which corresponds to 5 to 7 passes depending on the screw profile used. The quality of the $\mathrm{CNF}$ increases with the number of passes until reaching a plateau above $600-700 \mathrm{kWh} / \mathrm{t}$ humid.

(a)

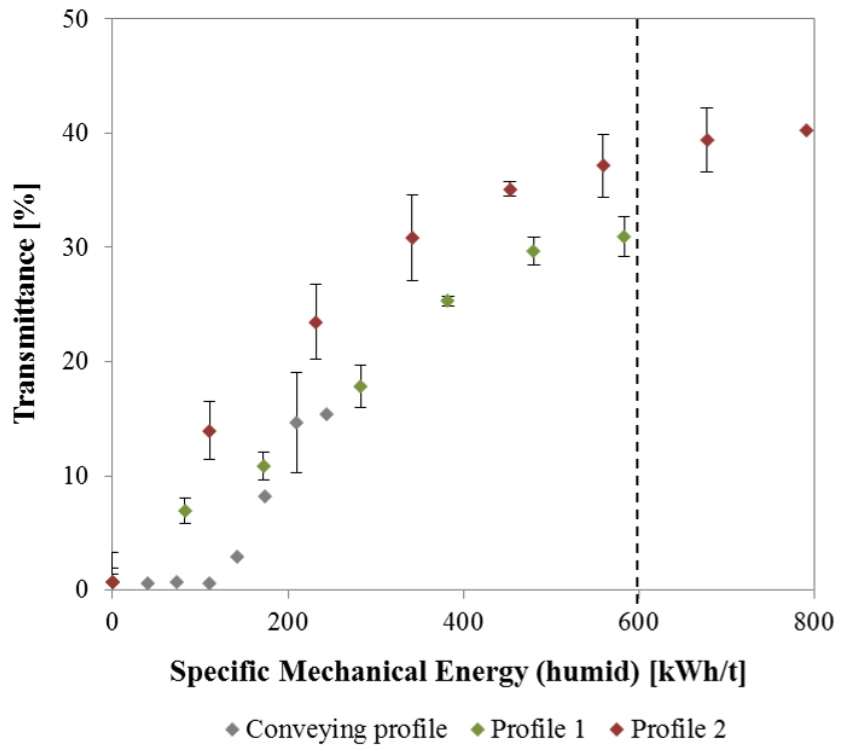

(b)

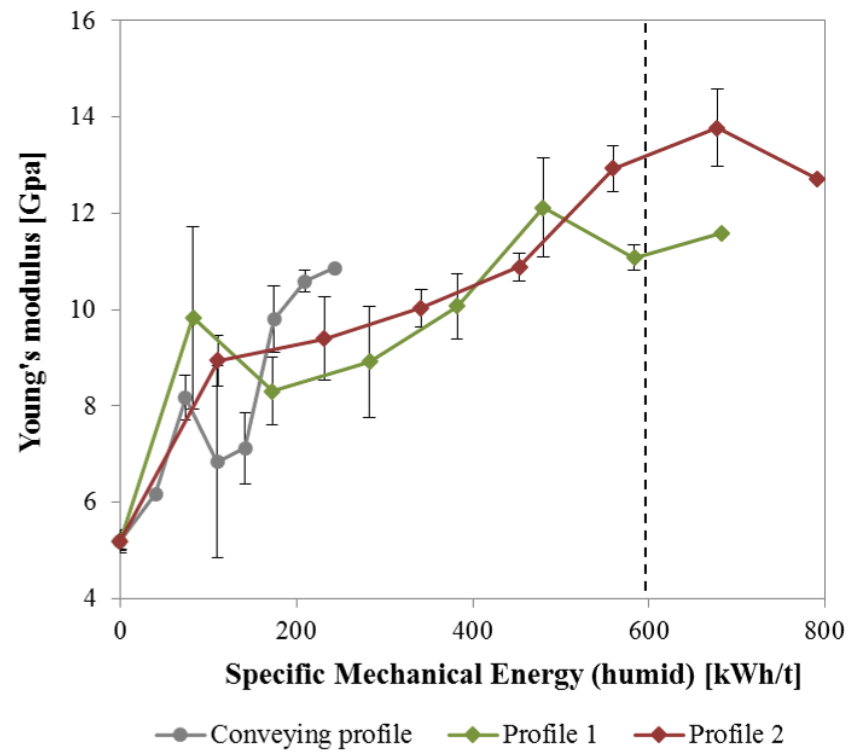

"Figure 3. Evolution of the CNF quality obtained with different number of passes through the TSE equipped with different screws profiles with the energy consumption: (a) Transmittance, the casted films have equivalent thicknesses around $35 \pm 5 \mu \mathrm{m}$ and (b) Young's modulus. Each point for a given screw profile corresponds to an additional passes through the TSE"

Transmittance and Young's modulus of produced CNF change with the energy consumptions, i.e. with the number of passes, as reported in Figure 3. Transmittance and Young's modulus increase with the energy consumption and, whatever the screw profile, stabilize for an energy consumption around $600-700 \mathrm{kWh} / \mathrm{t}$ (humid). Fibers need at least this energy level to be correctly nanofibrillated by the TSE, whatever the screw profile. Further 
passes through the TSE (meaning higher energy consumption) will not lead to higher quality because at $600-700 \mathrm{kWh} / \mathrm{t}$ the maximum of the quality for a given screw profile is reached. Depending on the screw profile, 4 to 6 passes are required to reach this energy. The objective is now to find a screw design able to supply this energy in a single pass playing with the software.

\section{Proposition of an optimized screw profile and comparison with other profiles}

The previous results and the simulation software were used to design a screw profile able to supply $600-700 \mathrm{kWh} / \mathrm{t}$ (humid) in 1 pass. Different screw profiles were designed and the extrusion was simulated. Changes were done until obtaining a screw profile able to provide $600-700 \mathrm{kWh} / \mathrm{t}$ humid in one pass. The final profile, reported in Figure 1, is called "New Profile”. It contains 6 shearing zones with mainly left-handed staggering. The shearing zones are shorter than the one of profiles 1 and 2 but they essentially contain reverse elements which is much more impacting. Finally, the total length of shearing zones is higher in the new profile than in profiles 1 and 2 .

To estimate the optimal processing conditions using the New profile, different conditions were simulated using the software and results are reported in Figure 4, where isovalues of SME and final temperature have been plotted as function of screw speed and feed rate. 
(a)

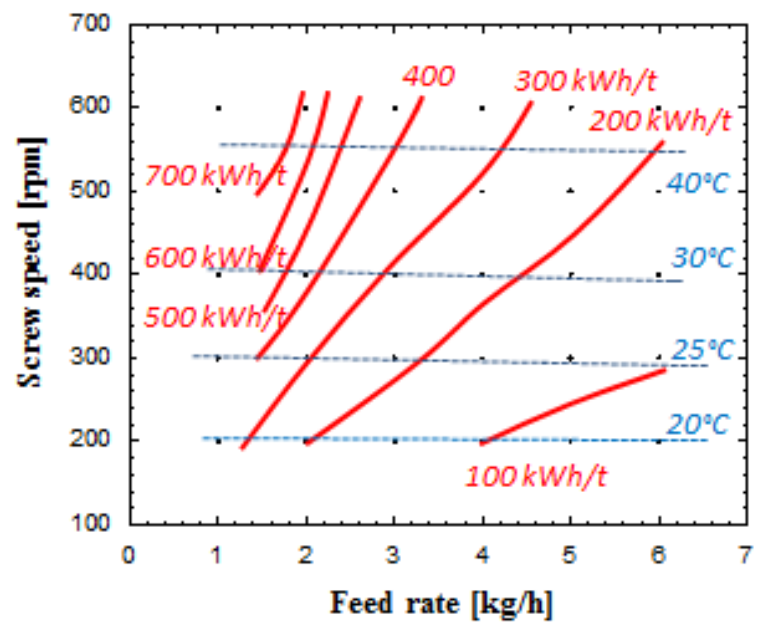

(b)

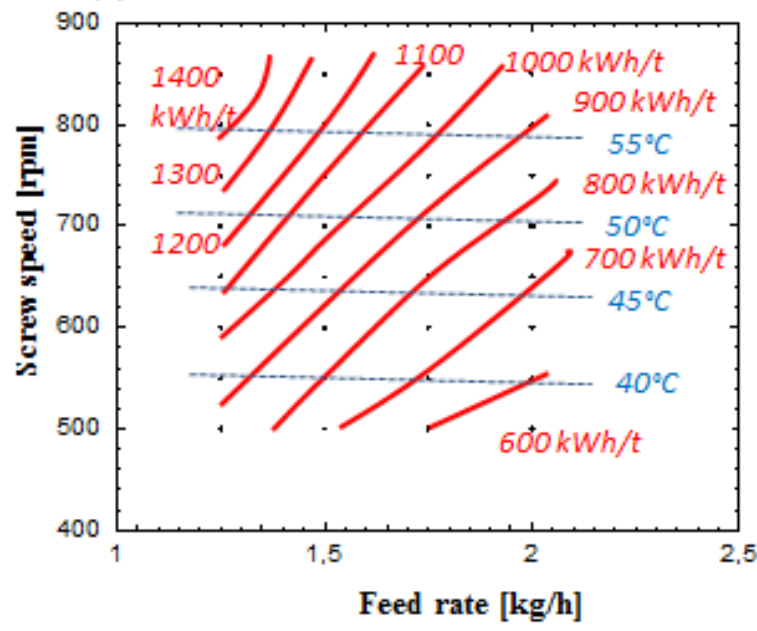

"Figure 4. TSE processing conditions to reach different energy consumptions (humid matter) (a) for low screw speed and various feed rate and (b) for low feed rate and high screw speed"

Obviously, SME, calculated as exposed in Equation (1), increases with the screw speed and decreases with the feed rate. Indeed, the screw speed is present at the nominator and the feed rate at the denominator of the SME equation. Those evolutions allow producing CNF of different quality depending on the energy, without changing the screw profile. Final temperature increases with the screw speed, quite independently of the feed rate. At high levels of SME, the final temperature could appear as a limitation. Indeed for high temperature, the pulp started to dry and hence to clog into the extruder. However, for SME between 600 and $700 \mathrm{kWh} / \mathrm{t}$ (humid matter), a temperature between 30 and $40^{\circ} \mathrm{C}$ should be reached which is acceptable. In our case, even at $45^{\circ} \mathrm{C}$, no problem was reported. To conclude, a feed rate around 1 and $2 \mathrm{~kg} / \mathrm{h}$ (wet) and a screw speed between 500 and $600 \mathrm{rpm}$ should be used to provide $700 \mathrm{kWh} / \mathrm{t}$ in one pass using this new screw profile.

The optimized new profile and the new extrusion conditions will now be compared to the profile 2 combined to other extrusion conditions. Both profiles were not tested using the same speed and feed rate, due to the optimization, which can induce some changes but the idea is to 
improve the nanofibrillation efficiency increasing the productivity and decreasing the energy consumption compared to the previous study, namely using profile $2,400 \mathrm{rpm}$ and $50 \mathrm{~g} / \mathrm{min}$.

The configuration of the new profile increases the residence time in the shearing zones and hence increases the cumulated strain. Plus, the shearing rates imposed by the two profiles are different as shown in Figure 5. The cumulated strain and the SME along the two screw profiles were evaluated using Ludovic ${ }^{\circledR}$ software and represented in Figure 5. They depend on the screw profile but also on the conditions of speed and feed rate used. The cumulated strain is much higher in the New profile: at $500 \mathrm{rpm}$ and $30 \mathrm{~g} / \mathrm{min}$ than in the profile 2 at $400 \mathrm{rpm}$ and $50 \mathrm{~g} / \mathrm{min}$. Each mixing zone of the New profile increases the cumulated strain of around 5000 whereas that of the profile 2 only increases the cumulated strain of 3000 . This can be explained by the difference in speed and feed rate. Plus, as already explained, the New profile presents six shearing zones whereas the profile 2 has only three which considerably affects the process. Finally, the cumulated strain transferred to the fibers in one pass through the New profile is 3 times higher than the one created by the profile 2 .

Same evolution is reported for the SME. It is multiplied by 4.5 using the New profile instead of the profile 2. To conclude, this new profile with the new extrusion conditions should be more efficient than profile 2 to nanofibrillate the cellulose pulp. Finally, in one pass, the energy consumed for the given conditions is around $450 \mathrm{kWh} / \mathrm{t}$ (humid matter) which is lower than the target of $600-700 \mathrm{kWh} / \mathrm{t}$, but still in the good order of magnitude. 

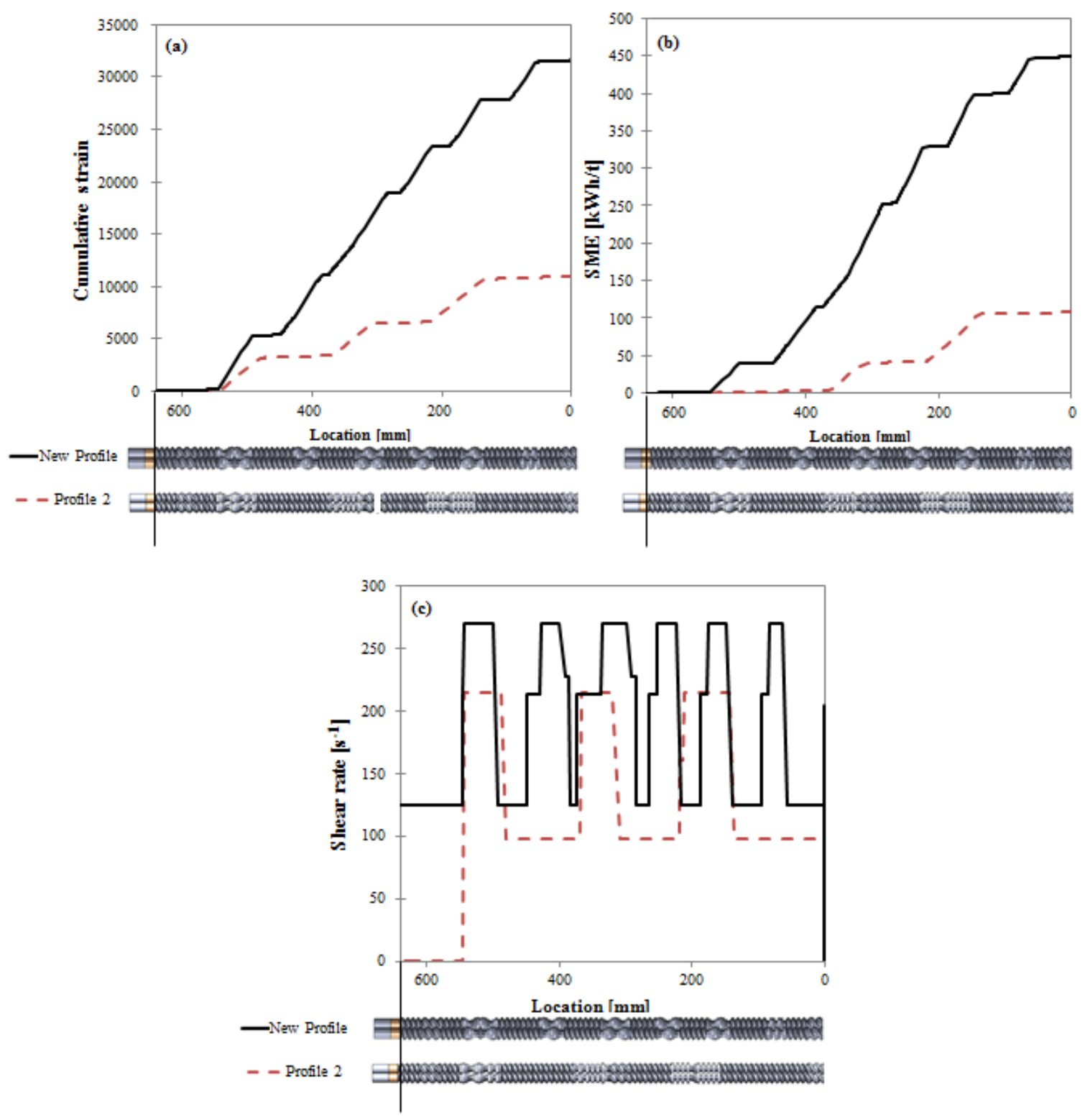

"Figure 5. Evolution of the cumulated strain (a), the SME (b) and the shear rate (c) along the two tested screw profiles with a screw speed and a feed rate of $500 \mathrm{rpm}$ and $1.8 \mathrm{~kg} / \mathrm{h}$ (humid) for the New profile and $400 \mathrm{rpm}$ and $3 \mathrm{~kg} / \mathrm{h}$ (humid) for the profile $2 . "$

\section{Production of CNF using the optimized profile}

The CNF produced with the New profile (500 rpm, $1.8 \mathrm{~kg} / \mathrm{h}, 20 \mathrm{wt} \%$ ) were compared with those produced using the profile 2 (400 rpm, $3 \mathrm{~kg} / \mathrm{h}, 20 \mathrm{wt} \%$ ). 
The two profiles present different designs and have been tested using different conditions, which leads to different energy consumption at each pass as reported in Table 1. As expected, the New profile consumes much more energy than the profile 2 and each additional pass consumes much more energy. In one pass, fibers will receive the same amount of energy, around $2,000 \mathrm{kWh} / \mathrm{t}$ (dry matter), than in 4 passes through the profile 2 which confirms the higher impact of this new profile. In one pass, the energy consumed is only equal to 420 $\mathrm{kWh} / \mathrm{t}$ (humid). However, after two passes, $800 \mathrm{kWh} / \mathrm{t}$ (humid) have been consumed. Some additional elements or other conditions could probably allow to reach the target SME (i.e. 700 $\mathrm{kWh} / \mathrm{t}$ ) in one pass.

The effect of the New profile on cellulose fibers will now be evaluated. The objective is to produce $\mathrm{CNF}$ in 1 pass or by default to decrease the number of passes compared to the profile 2.

Optical microscopy images of extruded CNF were taken and exposed in Figure 6,a. No large differences are observed between the CNF obtained via the two profiles, whatever the number of passes. Residual fibers are still visible after 1 pass through the New profile and the fiber content tends to decrease with the number of passes. ${ }^{22}$ However, the impact of the TSE on the cellulosic pulp is clear regarding the evolution of the fiber morphology on Figure 6 before and after extrusion. Moreover, the macroscopic size required in the $\mathrm{QI}^{*}$ calculation, and shown in Table 1, is almost the same whatever the screw profile and the number of passes. Despite the huge differences in energy consumption for the two profiles, the CNF produced present the same morphology at micrometric scale. However, optical images represent only the macroscopic part of the CNF suspensions and should be completed by others characterizations before any conclusion. 
TEM analysis were also performed to observe the CNF. Very thin nanometric fibers are observed confirming the efficiency of the TSE to produce CNF. After one pass through the new profile or four passes through the new profile or the profile 2, nanofibers are observed. The CNF obtained have a diameter around $21.9 \pm 8.5,20.2 \pm 10.6$ and $19.7 \pm 7.9 \mathrm{~nm}$ for respectively CNF obtained with Profile $2-4 p$, New profile $-1 P$ and New profile $-4 p$.
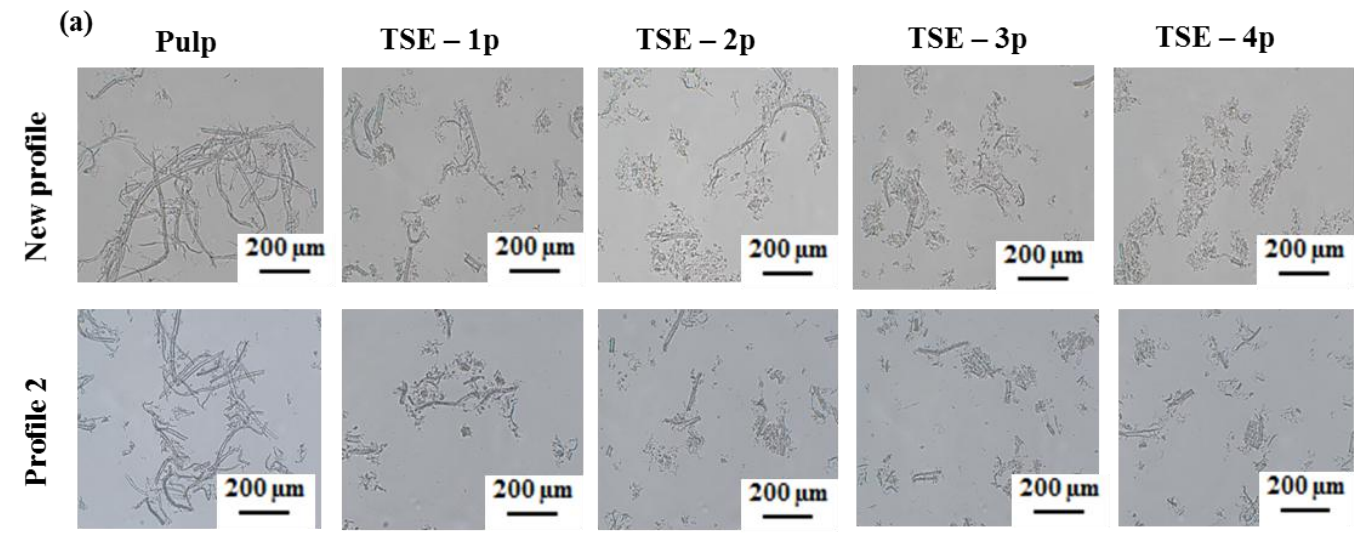

(b)
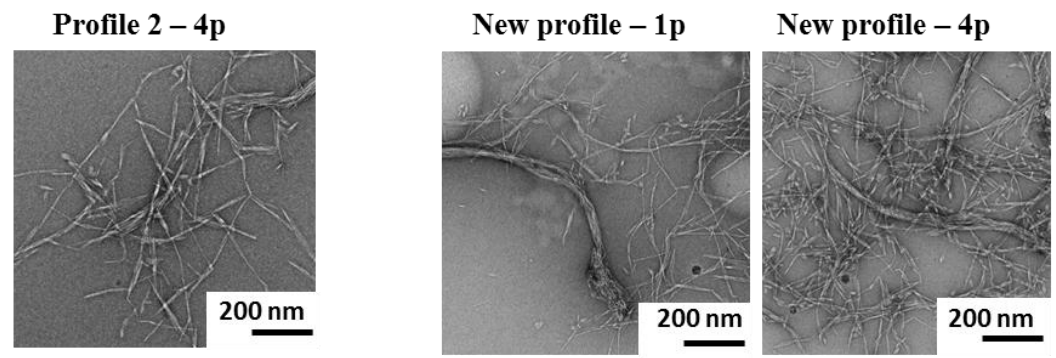

"Figure 6. Fibers morphology after enzymatic treatment and 1 to 4 passes through the TSE equipped with the New profile or the profile 2: (a) optical microscopy images and (b) TEM analysis"

CNF suspensions morphologies were also evaluated using MorFi analysis (Table 1). Fiber content decreases and fine content increases with the energy consumption due to effective nanofibrillation. ${ }^{22}$ Compared to the refined non extruded fibers, the number of residual fibers is considerably decreased and the quantity of fines increased. For an energy consumption around 2,500 $\mathrm{kWh} / \mathrm{t}$ (dry matter), New profile and profile 2 lead to CNF suspensions with the same amount of fibers and fines, namely 38-40 millions/g of pulp and 48-50\% in area, respectively. However, this corresponds to 4 passes through the profile 2 whereas only 1 pass 
is required through the New profile. This is also confirmed regarding the nanofiber size measurement on TEM images.

From a morphology point of view, the New profile attains the objective to produce CNF of equivalent quality in one pass without increasing the energy consumed. However, this profile could lead to stronger fiber degradation.

Cellulose fibers degree of polymerization was then measured to evaluate the impact of this new profile on the fiber degradation. TSE leads to DP decrease as the other mechanical processes used to produce cellulose nanofibrils. ${ }^{22}$ However, enzymatic pretreatment of the cellulose fibers is responsible of the major decrease of the DP. CNF obtained via the two tested profiles present the same DP, namely 270 after 1 pass for both profiles and 235 or 260 for CNF obtained after 4 passes through the profile 2 or through the New profile, respectively. The optimized profile does not further degrade cellulose fibers than the other tested profile.

Characterization of CNF is still challenging. ${ }^{32}$ In this study, CNF suspensions were evaluated using several methods and the simplified quality index QI*31 (Table 1) as exposed in Equation (2).

Young's modulus around 12-14 GPa are measured for CNF obtained with the New profile whatever the energy consumption. The obtained Young's modulus is much higher than the one reported for the refined non extruded enzymatic fibers, confirming the nanofibrillation. At fixed energy, the new profile leads to CNF with higher Young's modulus than CNF produced with the profile 2 whereas fibers morphologies evaluated by MorFi were almost the same. However, this is explained by the fact that MorFi cannot detect the nanofibrillated part due to the camera resolution. In one pass through the New profile, higher Young's moduli than after at least 4 passes through the profile 2 are obtained. Values obtained for the profile 2 will probably stabilize after 5 passes, and the data reached should not exceed $14 \mathrm{GPa}$, according to 
the previous studies, meaning that in one pass through the optimized profile, the plateau value of the profile 2 is reached. In one pass and consuming 2,500 $\mathrm{kWh} / \mathrm{t}$ (dry matter), the New profile leads to sufficient nanofibrillation to present mechanical properties in accordance with the literature. ${ }^{14,22,43-45}$

The nanosized fraction of the pulp passed through the profile 2 increases from $59.8 \pm 5.2 \%$ to $74.2 \pm 9.8 \%$ and that passed through the New profile reached around $70 \%$ directly after one pass. Turbidities are constant and almost the same, around $410 \pm 20$ and $380 \pm 11$ NTU for the pulp passed through the profile 2 and the New profile respectively, confirming that suspensions have similar properties.

Moreover, no evolution in any characterization techniques is reported with the number of passes through the New profile and further passes do not improve the nanofibrillation. The New profile designed to reach the plateau value observed for the other profiles during the first pass, successfully produces high quality CNF.

"Table 1. Characterizations of the produced CNF."

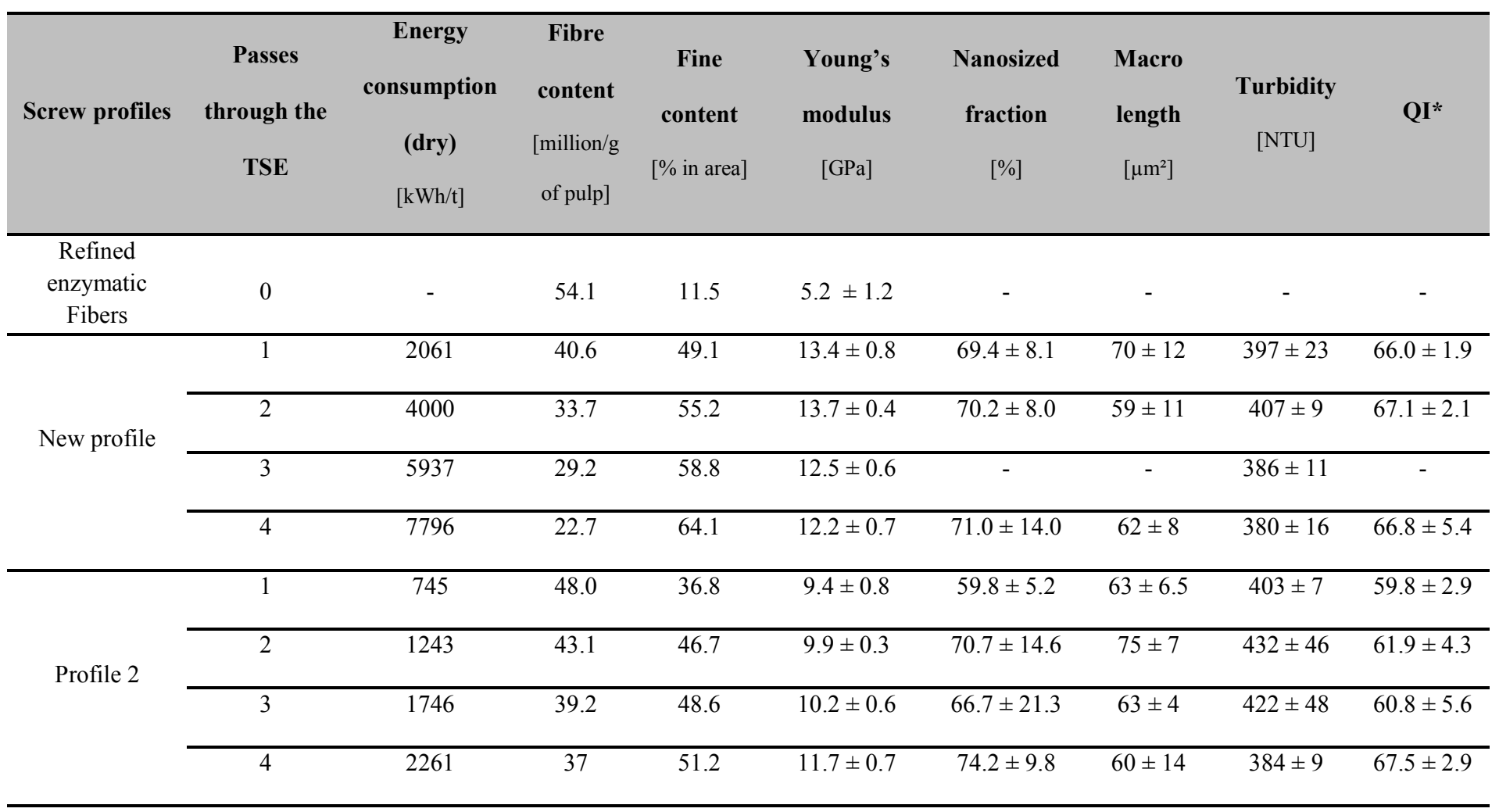


Transmittance of casted films were measured and reported in Figure 7 in order to evaluate CNF films transparency. Very transparent films are obtained directly after 1 pass through the New profile whereas the films formed with the fibers are not transparent. Same conclusion as for the other characterizations techniques can be drawn. However, the transmittance reached in one pass is not at the plateau value and it increases with the number of passes, whereas the plateau value seems reached for the profile 2 which is probably due to slight CNF size reduction and suspension homogenization. However, a lot of energy is required just to improve the transparency without increasing the global quality of the CNF, whereas highly transparent films are already obtained in the first pass.

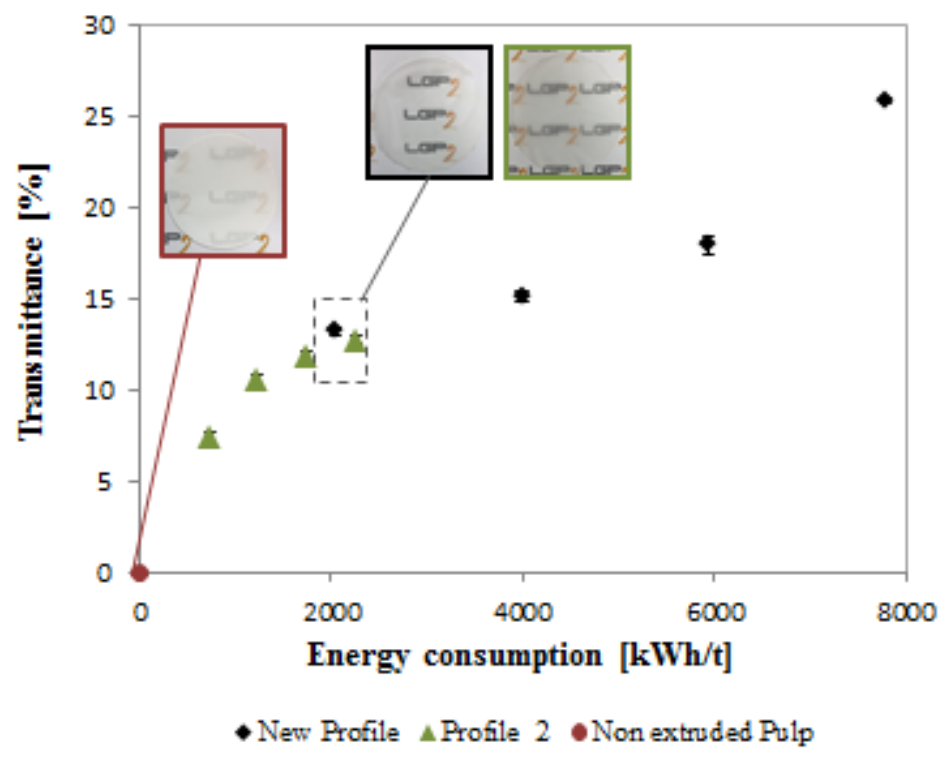

"Figure 7. Transmittance of casted films of CNF produced via the optimized profile and the profile 2. The casted films have equivalent thicknesses around $35 \pm 5 \mu \mathrm{m} "$

Finally, the simplified quality index was calculated. The objective is to compare and classify the CNF suspensions using only one data. As expected, same evolutions and observations are reported for the simplified quality index results, shown in Table 1 and Figure 8. The plateau value is reached at the first pass through the New profile and similar results are obtained than after at least 4 passes through the profile 2 consuming the same energy. QI* 
around 68 are evaluated which is a little bit lower compared to the literature ${ }^{22,31,45}$ but the produced CNF can easily compete with commercial ones. ${ }^{31}$

To conclude, high quality CNF are obtained in one pass through the TSE consuming only 2,100 $\mathrm{kWh} / \mathrm{t}$ (dry matter) which was the objective. This should allow an easier industrialization of such process, improving the productivity by at least 3 . Indeed, considering similar quality after 1 pass through the New profile and 4 passes through the profile 2 , the productivity is completely different as shown in Figure 8 . With New profile, $0.36 \mathrm{~kg} / \mathrm{h}$ of dry CNF (or $1.8 \mathrm{~kg} / \mathrm{h}$ in humid) can be produced consuming 2,100 $\mathrm{kWh} / \mathrm{t}$ whereas, in case of profile 2 , only $0.12 \mathrm{~kg} / \mathrm{h}$ dry (or $0.6 \mathrm{~kg} / \mathrm{h}$ in humid) can be produced consuming 2,200 kWh/t.

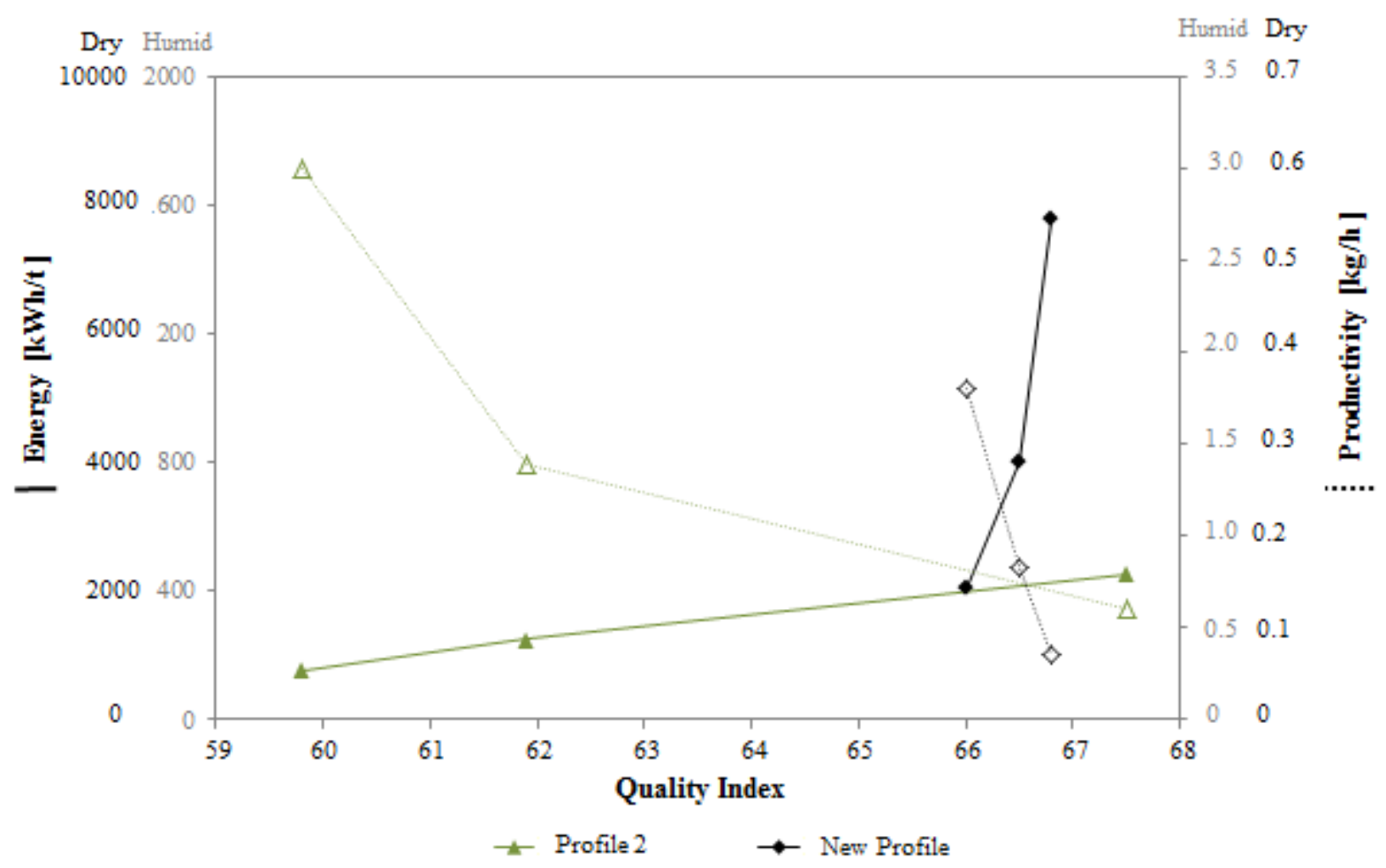

"Figure 8. CNF production by TSE: comparison of the productivity using the different screw profiles. The blanked points correspond to the productivity and the filled one to the energy consumption." 


\section{Conclusion}

As an attempt to optimize the CNF production by twin-screw extrusion, a simulation software was used to design an adapted screw profile and optimal extrusion conditions. First, the CNF pulp behavior was defined and the validity of the simulation checked. Then the proposed screw profile was tested and compared with another profile. The proposed new screw profile imparts higher strain (x3), and higher SME (x 4.5) in one pass but the processing conditions imposed do not allow to reach $600-700 \mathrm{kWh} / \mathrm{t}$ (humid) which was the targeted value. However, this screw profile composed of 6 shearing zones equipped essentially with left-handed staggered disks produces CNF in one pass with the same quality than the one produced via at least four (or more) passes through another profile. Similar Young's modulus (12 GPa) and same simplified quality index (around 68) are measured. Further passes through this new profile do not increase the quality insofar as the plateau value is reached in the first pass which was the target of the simulation. High quality CNF can now be produced in one pass through a TSE consuming only $2,500 \mathrm{kWh} / \mathrm{t}$ dry (or 3,100 $\mathrm{kWh} / \mathrm{t}$ taking into account the refining step).

\section{ACKNOWLEDGMENTS}

LGP2 is part of the LabEx Tec 21 (Investissements d'Avenir) and PolyNat Carnot Institutes. This research was supported by Institut Carnot Polynat (Grant agreement $n^{\circ}$ ANR-16-CARN-0025-01), Centre Technique du Papier (Grenoble, France) and LabEx Tec 21 (Grant agreement $n^{\circ}$ ANR-11LABX-0030). The authors want to thank Jean Luc Putaux and Christine Lancelon Pin from the Cermav (Grenoble) for the TEM analysis. 


\section{REFERENCES}

(1) Turbak, A. F.; Snyder, F. .; Sandberg, K. . Microfibrillated Cellulose, a New Cellulose Product: Properties, Uses, and Commercial Potential. J Appl Polym Sci Appl Polym Symp U. S. 1983, $37,815-827$.

(2) Lavoine, N.; Desloges, I.; Dufresne, A.; Bras, J. Microfibrillated Cellulose - Its Barrier Properties and Applications in Cellulosic Materials: A Review. Carbohydr. Polym. 2012, 90 (2), 735764. https://doi.org/10.1016/j.carbpol.2012.05.026.

(3) Bardet, R.; Bras, J. Cellulose Nanofibers and Their Use in Paper Industry. In Handbook of green materials; 2014; pp 207-232.

(4) Gumrah Dumanli, A. Nanocellulose and Its Composites for Biomedical Applications. Curr. Med. Chem. 2017, 24 (5), 512-528. https://doi.org/10.2174/0929867323666161014124008.

(5) Jorfi, M.; Foster, E. J. Recent Advances in Nanocellulose for Biomedical Applications. J. Appl. Polym. Sci. 2015, 132 (14), n/a-n/a. https://doi.org/10.1002/app.41719.

(6) Isogai, A.; Saito, T.; Fukuzumi, H. TEMPO-Oxidized Cellulose Nanofibers. Nanoscale 2011, 3 (1), 71-85. https://doi.org/10.1039/C0NR00583E.

(7) Naderi, A.; Lindström, T.; Sundström, J.; Pettersson, T.; Flodberg, G.; Erlandsson, J. Microfluidized Carboxymethyl Cellulose Modified Pulp: A Nanofibrillated Cellulose System with Some Attractive Properties. Cellulose 2015, 22 (2), 1159-1173. https://doi.org/10.1007/s10570-0150577-3.

(8) Naderi, A.; Lindström, T.; Sundström, J. Carboxymethylated Nanofibrillated Cellulose: Rheological Studies. Cellulose 2014, 21 (3), 1561-1571. https://doi.org/10.1007/s10570-014-0192-8.

(9) Noguchi, Y.; Homma, I.; Matsubara, Y. Complete Nanofibrillation of Cellulose Prepared by Phosphorylation. Cellulose 2017, 24 (3), 1295-1305. https://doi.org/10.1007/s10570-017-1191-3. 
(10) Ghanadpour, M.; Carosio, F.; Larsson, P. T.; Wågberg, L. Phosphorylated Cellulose Nanofibrils: A Renewable Nanomaterial for the Preparation of Intrinsically Flame-Retardant $\begin{array}{lllll}\text { Materials. } & \text { Biomacromolecules } & 2015, & 16 & (10),\end{array}$ https://doi.org/10.1021/acs.biomac.5b01117.

(11) Naderi, A.; Lindström, T.; Weise, C. F.; Flodberg, G.; Sundström, J.; Junel, K.; Erlandsson, J.; Runebjörk, A. M. Phosphorylated Nanofibrillated Cellulose: Production and Properties. Nord. Pulp Pap. Res. J. 2016, 31 (01), 020-029. https://doi.org/10.3183/NPPRJ-2016-31-01-p020-029.

(12) Rol, F.; Belgacem, M. N.; Gandini, A.; Bras, J. Recent Advances in Surface-Modified Cellulose Nanofibrils. Prog. Polym. Sci. 2018. https://doi.org/10.1016/j.progpolymsci.2018.09.002.

(13) Spence, K. L.; Venditti, R. A.; Rojas, O. J.; Habibi, Y.; Pawlak, J. J. A Comparative Study of Energy Consumption and Physical Properties of Microfibrillated Cellulose Produced by Different Processing Methods. Cellulose 2011, 18 (4), 1097-1111. https://doi.org/10.1007/s10570-011-9533-z.

(14) Nair, S. S.; Zhu, J. Y.; Deng, Y.; Ragauskas, A. J. Characterization of Cellulose Nanofibrillation by Micro Grinding. J. Nanoparticle Res. 2014, 16 (4), 2349. https://doi.org/10.1007/s11051-014-2349-7.

(15) Naderi, A.; Lindström, T.; Sundström, J. Repeated Homogenization, a Route for Decreasing the Energy Consumption in the Manufacturing Process of Carboxymethylated Nanofibrillated Cellulose? Cellulose 2015, 22 (2), 1147-1157. https://doi.org/10.1007/s10570-015-0576-4.

(16) Ho, T. T. T.; Abe, K.; Zimmermann, T.; Yano, H. Nanofibrillation of Pulp Fibers by TwinScrew Extrusion. Cellulose 2014, 22 (1), 421-433. https://doi.org/10.1007/s10570-014-0518-6.

(17) Baati, R.; Magnin, A.; Boufi, S. High Solid Content Production of Nanofibrillar Cellulose via $\begin{array}{llllll}\text { Continuous } & \text { Extrusion. } & \text { ACS } & \text { Sustain. }\end{array}$ https://doi.org/10.1021/acssuschemeng.6b02673. 
(18) Cobut, A.; Sehaqui, H.; Berglund, L. A. Cellulose Nanocomposites by Melt Compounding of TEMPO-Treated Wood Fibers in Thermoplastic Starch Matrix. BioResources 2014, 9 (2), 3276-3289. https://doi.org/10.15376/biores.9.2.3276-3289.

(19) Hietala, M.; Rollo, P.; Kekäläinen, K.; Oksman, K. Extrusion Processing of Green Biocomposites: Compounding, Fibrillation Efficiency, and Fiber Dispersion. J. Appl. Polym. Sci. 2014, 131 (6), 39981/1-399981/9. https://doi.org/10.1002/app.39981.

(20) Suzuki, K.; Okumura, H.; Kitagawa, K.; Sato, S.; Nakagaito, A. N.; Yano, H. Development of Continuous Process Enabling Nanofibrillation of Pulp and Melt Compounding. Cellulose 2013, 20 (1), 201-210. https://doi.org/10.1007/s10570-012-9843-9.

(21) Heiskanen, I.; Harlin, A.; Backfolk, K.; Laitinen, R. Process for Production of Microfibrillated Cellulose in an Extruder and Microfibrillated Cellulose Produced According to the Process. WO2011051882 (A1), May 5, 2011.

(22) Rol, F.; Karakashov, B.; Nechyporchuk, O.; Terrien, M.; Meyer, V.; Dufresne, A.; Belgacem, M. N.; Bras, J. Pilot-Scale Twin Screw Extrusion and Chemical Pretreatment as an Energy-Efficient Method for the Production of Nanofibrillated Cellulose at High Solid Content. ACS Sustain. Chem. Eng. 2017, 5 (8), 6524-6531. https://doi.org/10.1021/acssuschemeng.7b00630.

(23) Vergnes, B.; Valle, G. D.; Delamare, L. A Global Computer Software for Polymer Flows in Corotating Twin Screw Extruders. Polym. Eng. Sci. 38 (11), 1781-1792. https://doi.org/10.1002/pen.10348.

(24) Berzin, F.; Beaugrand, J.; Dobosz, S.; Budtova, T.; Vergnes, B. Lignocellulosic Fiber Breakage in a Molten Polymer. Part 3. Modeling of the Dimensional Change of the Fibers during Compounding by Twin Screw Extrusion. Compos. Part Appl. Sci. Manuf. 2017, 101, 422-431. https://doi.org/10.1016/j.compositesa.2017.07.009. 
(25) Durin, A.; De Micheli, P.; Ville, J.; Inceoglu, F.; Valette, R.; Vergnes, B. A Matricial Approach of Fibre Breakage in Twin-Screw Extrusion of Glass Fibres Reinforced Thermoplastics. Compos. Part Appl. Sci. Manuf. 2013, 48, 47-56. https://doi.org/10.1016/j.compositesa.2012.12.011.

(26) Della Valle, G.; Berzin, F.; Vergnes, B. Modeling of Twin Screw Extrusion Process for Food Products Design and Process Optmieation. In Advances in food extrusion technology; Medeni Maskan Aylin Altan, 2011; p 28.

(27) Vergnes, B.; Berzin, F. Modelling of Flow and Chemistry in Twin Screw Extruders. Plast. Rubber Compos. 2004, 33 (9-10), 409-415. https://doi.org/10.1179/174328904X24916.

(28) Berzin, F.; Vergnes, B.; Beaugrand, J. Evolution of Lignocellulosic Fibre Lengths along the Screw Profile during Twin Screw Compounding with Polycaprolactone. Compos. Part Appl. Sci. Manuf. 2014, 59, 30-36. https://doi.org/10.1016/j.compositesa.2013.12.008.

(29) Lafleur, P. G.; Vergnes, B. Polymer Extrusion; John Wiley \& Sons, 2014.

(30) Berzin, F.; Tara, A.; Tighzert, L.; Vergnes, B. Importance of Coupling between Specific Energy and Viscosity in the Modeling of Twin Screw Extrusion of Starchy Products. Polym. Eng. Sci. 2010, 50 (9), 1758-1766. https://doi.org/10.1002/pen.21702.

(31) Desmaisons, J.; Boutonnet, E.; Rueff, M.; Dufresne, A.; Bras, J. A New Quality Index for Benchmarking of Different Cellulose Nanofibrils. Carbohydr. Polym. 2017, 174, 318-329. https://doi.org/10.1016/j.carbpol.2017.06.032.

(32) Kangas, H.; Lahtinen, P.; Sneck, A.; Saariaho, A.-M.; Laitinen, O.; Hellén, E. Characterization of Fibrillated Celluloses. A Short Review and Evaluation of Characteristics with a Combination of Methods. Nord. Pulp Pap. Res. J. 2014, 29 (01), 129-143. https://doi.org/10.3183/NPPRJ-2014-2901-p129-143.

(33) Foster, E. J.; Moon, R. J.; Agarwal, U. P.; Bortner, M. J.; Bras, J.; Camarero-Espinosa, S.; Chan, K. J.; Clift, M. J. D.; Cranston, E. D.; Eichhorn, S. J.; et al. Current Characterization Methods 
for Cellulose Nanomaterials. Chem. Soc. Rev. 2018, 47 (8), 2609-2679. https://doi.org/10.1039/C6CS00895J.

(34) Nechyporchuk, O.; Belgacem, M. N.; Pignon, F. Rheological Properties of Micro/Nanofibrillated Cellulose Suspensions: Wall-Slip and Shear Banding Phenomena. Carbohydr. Polym. 2014, 112, 432-439. https://doi.org/10.1016/j.carbpol.2014.05.092.

(35) Naderi; Lindström. Rheological Measurements on Nanofibrillated Cellulose Systems: A Science in Progress. Nova Sci. Publ. Inc N. Y. 2015, 187-202.

(36) Grüneberger, F.; K?nniger, T.; Zimmermann, T.; Arnold, M. Rheology of Nanofibrillated Cellulose/Acrylate Systems for Coating Applications. Cellulose 2014, 21 (3), 1313-1326. https://doi.org/10.1007/s10570-014-0248-9.

(37) Lasseuguette, E.; Roux, D.; Nishiyama, Y. Rheological Properties of Microfibrillar Suspension of TEMPO-Oxidized Pulp. Cellulose 2008, 15 (3), 425-433. https://doi.org/10.1007/s10570-007-9184-2.

(38) Besbes, I.; Alila, S.; Boufi, S. Nanofibrillated Cellulose from TEMPO-Oxidized Eucalyptus Fibres: Effect of the Carboxyl Content. Carbohydr. Polym. 2011, 84 (3), 975-983. https://doi.org/10.1016/j.carbpol.2010.12.052.

(39) Agoda-Tandjawa, G.; Durand, S.; Berot, S.; Blassel, C.; Gaillard, C.; Garnier, C.; Doublier, J.L. Rheological Characterization of Microfibrillated Cellulose Suspensions after Freezing. Carbohydr. Polym. 2010, 80 (3), 677-686. https://doi.org/10.1016/j.carbpol.2009.11.045.

(40) Mohtaschemi, M.; Dimic-Misic, K.; Puisto, A.; Korhonen, M.; Maloney, T.; Paltakari, J.; Alava, M. J. Rheological Characterization of Fibrillated Cellulose Suspensions via Bucket Vane Viscometer. Cellulose 2014, 21 (3), 1305-1312. https://doi.org/10.1007/s10570-014-0235-1.

(41) Herrick, F. W.; Casebier, R. L.; Hamilton, J. K.; Sandberg, K. R. Microfibrillated Cellulose: Morphology and Accessibility. J Appl Polym Sci Appl Polym Symp U. S. 1983, 37. 
(42) Cox, W. P.; Merz, E. H. Correlation of Dynamic and Steady Flow Viscosities. J. Polym. Sci. 1958, 28 (118), 619-622. https://doi.org/10.1002/pol.1958.1202811812.

(43) Pei, A.; Butchosa, N.; Berglund, L. A.; Zhou, Q. Surface Quaternized Cellulose Nanofibrils with High Water Absorbency and Adsorption Capacity for Anionic Dyes. Soft Matter 2013, 9 (6), 2047. https://doi.org/10.1039/c2sm27344f.

(44) Sirviö, J. A.; Anttila, A.-K.; Pirttilä, A. M.; Liimatainen, H.; Kilpeläinen, I.; Niinimäki, J.; Hormi, O. Cationic Wood Cellulose Films with High Strength and Bacterial Anti-Adhesive Properties. Cellulose 2014, 21 (5), 3573-3583. https://doi.org/10.1007/s10570-014-0351-y.

(45) Rol, F.; Banvillet, G.; Meyer, V.; Petit-Conil, M.; Bras, J. Combination of Twin-Screw Extruder and Homogenizer to Produce High-Quality Nanofibrillated Cellulose with Low Energy Consumption. J. Mater. Sci. 2018, 1-12. https://doi.org/10.1007/s10853-018-2414-1. 


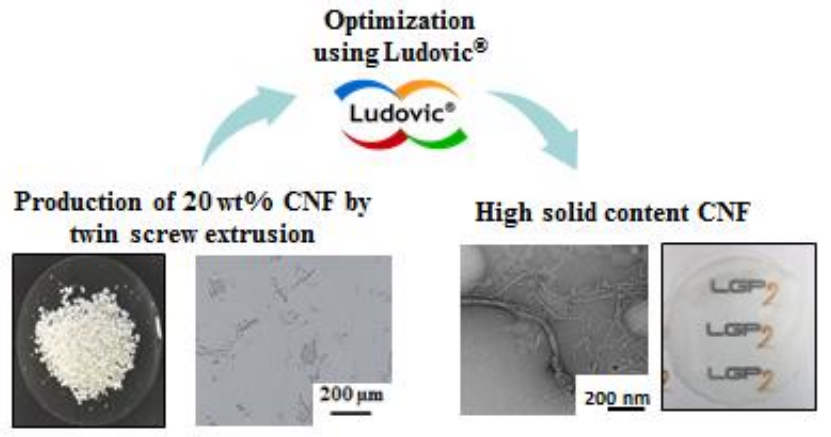

Synopsis. The production of cellulose nanofibrils by twin-screw extrusion was optimized using a simulation software to reduce the energy consumption and increase the productivity. 